\title{
Optimizing growth conditions for electroless deposition of Au films on Si(111) substrates
}

\author{
BHUVANA and G U KULKARNI* \\ Chemistry and Physics of Materials Unit and DST Unit on Nanoscience, Jawaharlal Nehru Centre for \\ Advanced Scientific Research, Jakkur PO, Bangalore 560 064, India
}

MS received 24 March 2006

\begin{abstract}
Electroless deposition of Au films on Si(111) substrates from fluorinated-aurate plating solutions has been carried out at varying concentrations, deposition durations as well as bath temperatures, and the resulting films were characterized by $\mathrm{X}$-ray diffraction, optical profilometry, atomic force microscopy and scanning electron microscopy. Depositions carried out with dilute plating solutions $(<0 \cdot 1 \mathrm{mM})$ at $28^{\circ} \mathrm{C}$ for $30 \mathrm{~min}$ produce epitaxial films exhibiting a prominent $\mathrm{Au}(111)$ peak in the diffraction patterns, while higher concentrations or temperatures, or longer durations yield polycrystalline films. In both epitaxial and polycrystalline growth regimes, the film thickness increases linearly with time, however, in the latter case, at a rate an order of magnitude higher. Interestingly, the surface roughness measured using atomic force microscopy shows a similar trend. On subjecting to annealing at $250^{\circ} \mathrm{C}$, the roughness of the film decreases gradually. Addition of poly (vinylpyrrolidone) to the plating solution is shown to produce a X-ray amorphous film with nanoparticulates capped with the polymer as evidenced by the core-level photoelectron spectrum. Nanoindentation using AFM has shown the hardness of the films to be much higher $(\sim 2 \cdot 19 \mathrm{GPa})$ than the bulk value.
\end{abstract}

Keywords. Electroless deposition; nanoindentation; surface morphology.

\section{Introduction}

Electroless deposition of metals on semiconductor surfaces is an important topic in view of its application in electronics (Khoperia et al 1997; Okinaka et al 1998; Osaka et al 2003), surface coatings (Pearlstein and Lawenheim 1974; Mallory and Hajdu 1990) and nanofabrication (Sugimura and Nakagiri 1995; Kobayashi et al 2000). By definition, it requires no external potential and the deposition is carried out usually in a fluoride solution, by the reduction of metal ions at a semiconductor surface. The half-cell reactions on a $\mathrm{Si}$ substrate are as follows:

$$
\begin{aligned}
& \text { Anodic: } \mathrm{Si}+6 \mathrm{HF} \rightarrow \mathrm{SiF}_{6}{ }^{2-}+6 \mathrm{H}^{+}+4 e^{-}, \\
& \text {Cathodic: } \mathrm{M}^{n+}+n e^{-} \rightarrow \mathrm{M}(\mathrm{M}=\text { metal }) .
\end{aligned}
$$

The advantages of electroless deposition are many: it is simple, relatively inexpensive and does not generally depend on the shape, size or conductivity of the substrate but yields high purity films. Using electroless deposition, several metals have been deposited on Si and Ge surfaces that include $\mathrm{Cu}$ (Nagahara et al 1993; Morinaga et al 1994; Norga et al 1997; Homma et al 1998; Magagnin et al 2001, 2003), Ni (Furukawa and Mehregany 1996; Gorostiza et al 2000; Li et al 2005), Al (Nagahara et al 1993), Sn

\footnotetext{
*Author for correspondence (kulkarni@jncasr.ac.in)
}

(Nagahara et al 1993), Pd (Nagahara et al 1993), Pt (Gorostiza et al 1996, 1997; Kuznetsov et al 2001), Ag (Shacham-Diamond et al 2000; Kalkan and Fonash 2005) and $\mathrm{Au}$ (Krikshtopaitis and Kudzhmauskaite 1971; Nagahara et al 1993; Magagnin et al 2002; Warren et al 2002). Magagnin et al (2001) reported improved adhesion of $\mathrm{Cu}$ films on $\mathrm{Si}$ substrates when sodium sulfate or ascorbic acid is added to the plating solution. They also examined the films by microindentation (Magagnin et al 2003). Homma et al (1998) monitored using STM, the nucleation and growth of $\mathrm{Cu}$ on $\mathrm{Si}(111)$. Mechanism of $\mathrm{Cu}$ ion reduction on $\mathrm{Si}$ in dilute HF solution has been discussed by Norga et al (1997). Gorostiza et al (2000) studied the electroless deposition of $\mathrm{Ni}$ on $\mathrm{Si}$ substrates by varying $\mathrm{pH}$ of the plating solution. At $\mathrm{pH}$ of $1 \cdot 2$, no deposition was seen while at $\mathrm{pH}$ of 8.0 , the Ni deposition was found to be rich. Furukawa and Mehregany (1996) have shown that optimal conditions of temperature and $\mathrm{pH}$ are necessary to obtain smooth Ni films. The effect of HF concentration on the initial stages of the electroless deposition of $\mathrm{Al}, \mathrm{Au}, \mathrm{Cu}, \mathrm{Sn}$ and $\mathrm{Pd}$ on $\mathrm{Si}(100)$, has been carefully studied by Nagahara et al (1993) using atomic force microscopy. The rate of metal deposition on the nature of the dopant has also been studied. For equal deposition times, more Pt was found to be deposited on $p$-Si substrates than on $n$-Si substrates (Gorostiza et al 1997). In some cases such as Pt on $p$-Si(100), both metal and its silicide have been detected (Gorostiza et al 1996). Recently, Kalkan and Fonash 
(2005) reported Ag nanoparticle ensembles on nanostructured Si films. Deposition of Au films from fluoride solutions on $\mathrm{Si}$ and Ge surfaces has been studied by Krikshtopaitis and Kudzhmauskaite (1971) about thirty years ago. Magagnin et al (2002) examined the orientation and chemical nature of the metal at $\mathrm{Au}-\mathrm{Si}$ and $\mathrm{Au}-\mathrm{Ge}$ interfaces. Using atomic force microscopy and surface diffraction, Warren et al (2002) studied the Au cluster formation as a function of concentration of the plating solution. The deposited films of $\mathrm{Au}$, especially of (111) orientation have been evaluated as substrates for organizing self-assembling molecules (Hou et al 1998, 1999).

We considered it interesting to investigate $\mathrm{Au}$ films on Si(111) surface prepared by electroless deposition under different plating conditions. For this purpose, we used plating solutions containing different concentrations of the gold precursor $\left(\mathrm{KAuCl}_{4}\right)$ and varied the rate of deposition as a function of time and temperature. An important finding from this part of the study is the set of optimal conditions to obtain well-oriented $\mathrm{Au}(111)$ films. We have monitored the orientation of the films using X-ray diffraction (XRD) and the surface morphology by atomic force microscopy (AFM). Nanoindentation using AFM was performed to determine the hardness. We have studied the growth process by measuring the film thickness using an optical profiler (OP). Furthermore, we have examined the effect of annealing at elevated temperatures for different durations. The influence of an additive to the plating solution, poly(vinylpyrrolidone), has also been examined. The composition of films in such cases was obtained using X-ray photoelectron spectroscopy (XPS). Thus, our study forms a systematic approach to Au plating on Si substrates.

\section{Experimental}

The Si(111) substrates were cleaned by sonicating in acetone and double distilled water and were UV irradiated at room temperature for $15 \mathrm{~min}$. They were cleaned further by heating at $80^{\circ} \mathrm{C}$ in piranha solution $\left(1: 2 \mathrm{H}_{2} \mathrm{O}_{2}: \mathrm{H}_{2} \mathrm{SO}_{4}\right)$ (Caution: this mixture reacts violently with organic matter) for $10 \mathrm{~min}$. Prior to deposition, the substrate was etched in concentrated $\mathrm{HF}$ for $10 \mathrm{~min}$, rinsed with double distilled water and dried under flowing argon. Immediately after, it was dipped without stirring in a fresh plating solution $(5 \mathrm{~mL})$ of $\mathrm{KAuCl}_{4}$ in $5 \mathrm{M} \mathrm{HF}$ with the concentration varying in the range $0.02-5 \mathrm{mM}$, taken in a teflon container. After a certain interval of time $(30-150 \mathrm{~min})$, the substrate deposited with the Au film was carefully rinsed with double distilled water and dried under argon. The film deposition has been carried out at various bath temperatures $\left(0-60^{\circ} \mathrm{C}\right)$. In some cases, the as-prepared samples were subjected to annealing up to $300^{\circ} \mathrm{C}$. Further in this study, the plating solution was added with surfactant, poly(vinylpyrrolidone) (PVP, $M_{\mathrm{W}} \sim 40,000 \mathrm{~g} \mathrm{~mol}^{-1}$ ) in the concentration range $0 \cdot 005-0 \cdot 1 \mathrm{mM}$. The conditions employed for preparing the different samples are listed in table 1.

XRD measurements were performed on a Miniflex (Rigaku, Japan) $\left(\mathrm{Cu} \mathrm{K}_{\alpha}, 1.5406 \AA\right.$; scan rate, $\left.1 \mathrm{deg} / \mathrm{min}\right)$. AFM measurements were made using a Digital Instruments Multimode head attached to a Nanoscope-IV controller (Veeco, USA). Standard $\mathrm{Si}_{3} \mathrm{~N}_{4}$ cantilevers were used for the normal topography and friction mode imaging in contact mode, and for the tapping mode, etched silicon cantilevers were employed. The rms roughness values were obtained from the image analysis tools available with the instrument.

Table 1. The plating conditions for various films.

\begin{tabular}{|c|c|c|c|c|}
\hline Sample number & $\begin{array}{l}\mathrm{KAuCl}_{4} \\
(\mathrm{mM})\end{array}$ & $\begin{array}{l}\text { Time of deposition } \\
\text { (min) }\end{array}$ & $\begin{array}{c}\text { Bath temperature } \\
\left({ }^{\circ} \mathrm{C}\right)\end{array}$ & $\begin{array}{l}\text { PVP additive } \\
(\mathrm{mM})\end{array}$ \\
\hline 1 & 0.02 & & & \\
\hline 2 & $0 \cdot 2$ & $\nabla$ & & \\
\hline 3 & 0.5 & 30 & & \\
\hline 4 & $1 \cdot 0$ & 4 & & \\
\hline 5 & $5 \cdot 0$ & $\mid$ & & \\
\hline 6 & & 5 & $\downarrow$ & \\
\hline 7 & & 10 & 28 & \\
\hline 8 & & 15 & 4 & \\
\hline 9 & & 20 & & \\
\hline 10 & & 45 & & \\
\hline 11 & & 60 & & \\
\hline 12 & $\nabla$ & 90 & & \\
\hline 13 & $0 \cdot 1$ & 120 & & \\
\hline 14 & $\Delta$ & 150 & & \\
\hline 15 & & & 0 & \\
\hline 16 & & $\nabla$ & 60 & \\
\hline 17 & & 30 & $\downarrow$ & 0.005 \\
\hline 18 & & $\Delta$ & 28 & 0.01 \\
\hline 19 & & & 4 & 0.04 \\
\hline 20 & | & 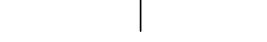 & & $0 \cdot 1$ \\
\hline
\end{tabular}


Nanoindentation experiments were performed in the tapping mode using a cantilever carrying a pyramidal diamond tip (spring constant, $278 \mathrm{Nm}^{-1}$ and resonance frequency, $52.8 \mathrm{~Hz}$ ). The indentation impression was also imaged

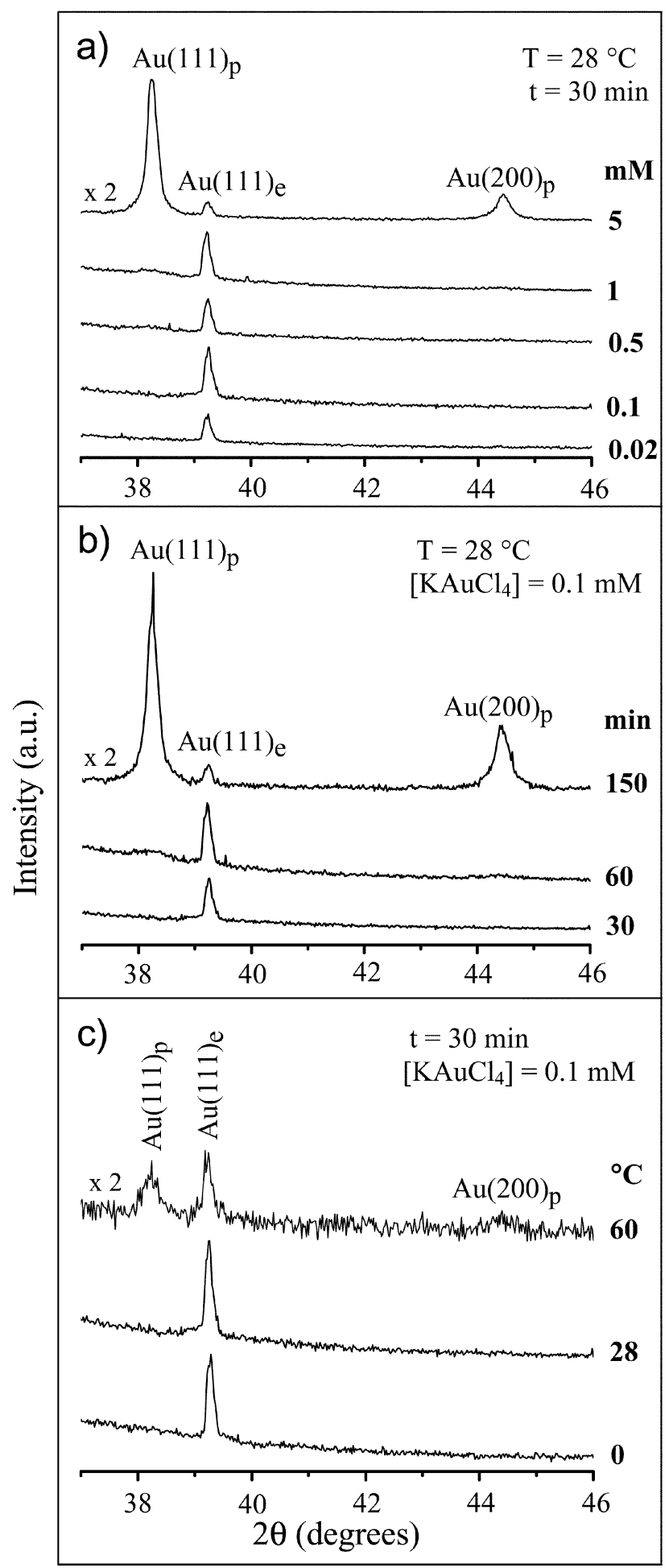

Figure 1. X-ray diffraction patterns of Au films deposited on $\mathrm{Si}(111)$ substrates while varying (a) concentration of $\mathrm{KAuCl}_{4}$, (b) deposition time and (c) bath temperature. with the same tip. The hardness was calculated from the load-displacement data obtained by nanoindentation. The $\mathrm{Au}(4 f)$ core-level spectra were collected using ESCALAB MK-IV spectrometer with an $\mathrm{Al} \mathrm{K}_{\alpha}$ source $(1486.6 \mathrm{eV})$. For thickness measurement, a step was created by partially dipping the Si substrate vertically in the plating solution. Thickness measurements were performed using a Wyko NT1100 optical profiler (Veeco, USA).

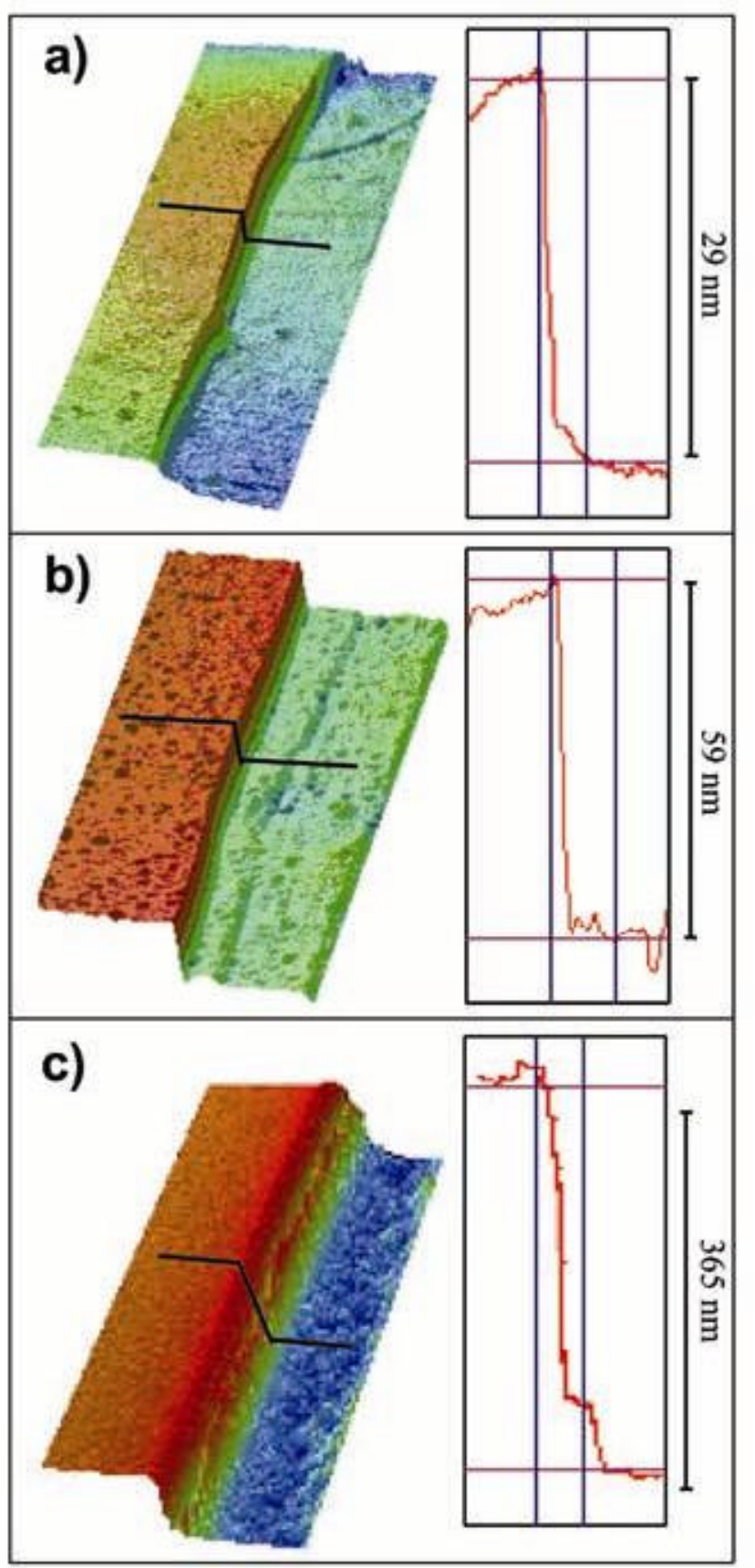

Figure 2. Profilometric measurements on Au films obtained by dipping $\mathrm{Si}$ substrates in the plating solution for (a) $30 \mathrm{~min}$, (b) $60 \mathrm{~min}$ and (c) $90 \mathrm{~min}$. The deposition was carried out under standard plating conditions $\left(0 \cdot 1 \mathrm{mM} \mathrm{KAuCl}_{4}, 28^{\circ} \mathrm{C}\right)$. 


\section{Results and discussion}

X-ray diffraction patterns of the Au films obtained under different deposition conditions are shown in figure 1. As shown in figure $1 \mathrm{a}$, for small concentrations of the aurate ion, say $0.02 \mathrm{mM}$, with a deposition time of $30 \mathrm{~min}$ at $28^{\circ} \mathrm{C}$ (sample 1, see table 1), we see only one peak in the diffraction pattern at $2 \theta$ of $39 \cdot 2^{\circ}$ corresponding to $d$-spacing of $2 \cdot 295 \AA$, matching closely with the $d_{111}$-spacing of the bulk Au (2.355 $\AA$ ). Similar observation has been made by Kuwahara et al (1994), who reported a difference in the $d$-spacing of $0.04 \AA$ for the epitaxial Au film on $\operatorname{Si}(111)$ grown by vacuum deposition. The intensity of the (111) diffraction peak grows gradually as the concentration of aurate ion is increased from 0.02 to $1 \mathrm{mM}$ (samples 1-4) with no evidence of other diffraction peaks. At higher concentrations ( $5 \mathrm{mM}$, sample 5 ), however, we observe additional peaks at $38.24^{\circ}$ and $44.42^{\circ}$ corresponding to bulk Au spacings of $d_{111}(2 \cdot 350 \AA)$ and $d_{200}(2 \cdot 039 \AA)$, respectively. The peak at $2 \cdot 295 \AA$ from the lower epitaxial layer is much reduced in intensity. In figures $1 \mathrm{~b}$ and $\mathrm{c}$ are shown the diffraction patterns obtained while varying the time of deposition and the bath temperature, respectively. Clearly, longer deposition durations and higher temperatures yield polycrystalline Au films. It may be noted from the intensity of (111) peak in the diffraction patterns that the amount of deposition is considerably low for deposition carried out at $60^{\circ} \mathrm{C}$ (sample 16), while for $0^{\circ} \mathrm{C}$ (sample 15) the intensity is comparable to the room temperature deposition (sample 2) (see figure 1c). Our study shows that among the various parameters, the deposition time gives a good control on the thickness of film.

As shown in figure 2 , the $\mathrm{Au}$ films obtained from a bath containing $0.1 \mathrm{mM} \mathrm{KAuCl}{ }_{4}$ at $28^{\circ} \mathrm{C}$, for 30,60 and 90 min (samples 2, 11 and 12) exhibit steps of 29, 59 and $365 \mathrm{~nm}$, respectively with respect to the Si substrate. Using AFM, we found the rms roughness of the films to be 7.9 , 12.8 and $17.1 \mathrm{~nm}$, respectively. Naturally, this sets a lower limit of thickness for a uniform $\mathrm{Au}$ film. In other words, the thickness of the film deposited by this method could be controlled within a few nanometres by varying the deposition time. Figure 3 shows that the rate of deposition as measured by OP, varies proportionally with time. During the first hour, the deposition is at the rate of $1.03 \mathrm{~nm} / \mathrm{min}$ (samples 2, 6-11) and at longer durations, there is almost an order of magnitude rise, $9 \cdot 04 \mathrm{~nm} / \mathrm{min}$ (samples 12-14). Referring to figure $1 \mathrm{~b}$, it is interesting to note that this change of behaviour in the film coincides with epitaxial growth of the film becoming polycrystalline. The rms roughness values obtained from contact AFM (see figure 3) also exhibit a similar trend, implying that a change in the rate of deposition owes much to the increased roughness from polycrystallinity.

In order to improve the texture, the film (sample 2) was subjected to annealing at elevated temperatures of $250^{\circ} \mathrm{C}$ and $300^{\circ} \mathrm{C}$. In figure 4 are shown AFM and diffraction measurements after annealing at $250^{\circ} \mathrm{C}$ for different time durations. As seen from figure $4 \mathrm{a}$, the deposited film is granular and the particulates appear agglomerated into islands measuring hundreds of nanometres. Annealing at $250^{\circ} \mathrm{C}$ for $2 \mathrm{~h}$ (figure $4 \mathrm{~b}$ ) improved the surface topography. With further annealing for $10 \mathrm{~h}$, the particles measuring $\sim 35 \mathrm{~nm}$ appear closely packed. Additional annealing, however, makes the particles grow almost three times bigger (see figure 4d). The roughness values obtained from AFM analysis (see inset of figure 4) show a sharp decrease from $\sim 12$ to $\sim 5 \mathrm{~nm}$ following annealing. Interestingly, the (111) oriented nature of the film remains almost unaffected as evident from the X-ray diffraction patterns shown along with the images. However, the film became essentially polycrystalline after annealing at $300^{\circ} \mathrm{C}$ for $1 \mathrm{~h}$.

We have made a detailed study on the influence of surfactant on the gold deposition. For this purpose, PVP was added in small concentrations under the standard plating conditions $\left(0.1 \mathrm{mM} \mathrm{KAuCl}{ }_{4}, 28^{\circ} \mathrm{C}, 30 \mathrm{~min}\right)$ and the results obtained are shown in figure 5. At smaller concentrations of PVP, 0.005 and $0.01 \mathrm{mM}$ (samples 17 and 18, respectively), the diffraction patterns in figure 4 a resemble closely with those without the additive (see figure 1a). In other words, the presence of PVP brings no noticeable change in the diffraction patterns at such low concentrations. In contrast, for higher concentrations, $\geq 0.04 \mathrm{mM}$ (samples 19 and 20), there is hardly any intensity in the diffraction pattern, as if the deposition process itself is hindered. The nature of the deposited material became more evident from the AFM and XPS analysis shown in figures $5 b$ and c. The AFM image in figure $5 \mathrm{~b}$ reveals the granular structure of the deposited material, with granules in the range of $80-$ $140 \mathrm{~nm}$. Each granule appears as an aggregate of particulates

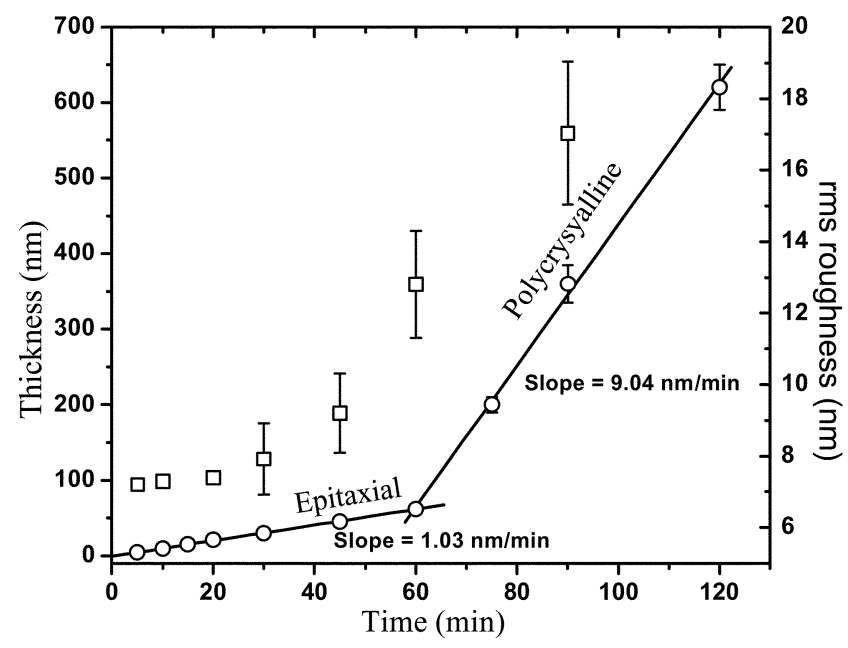

Figure 3. Variation in the thickness of the films (circles) as a function of time in the standard plating solution $(0.1 \mathrm{mM}$ $\left.\mathrm{KAuCl}_{4}, 28^{\circ} \mathrm{C}\right)$. The variation in the rms roughness values (squares) estimated from $2 \times 2 \mu^{2}$ area using AFM, is also shown. 

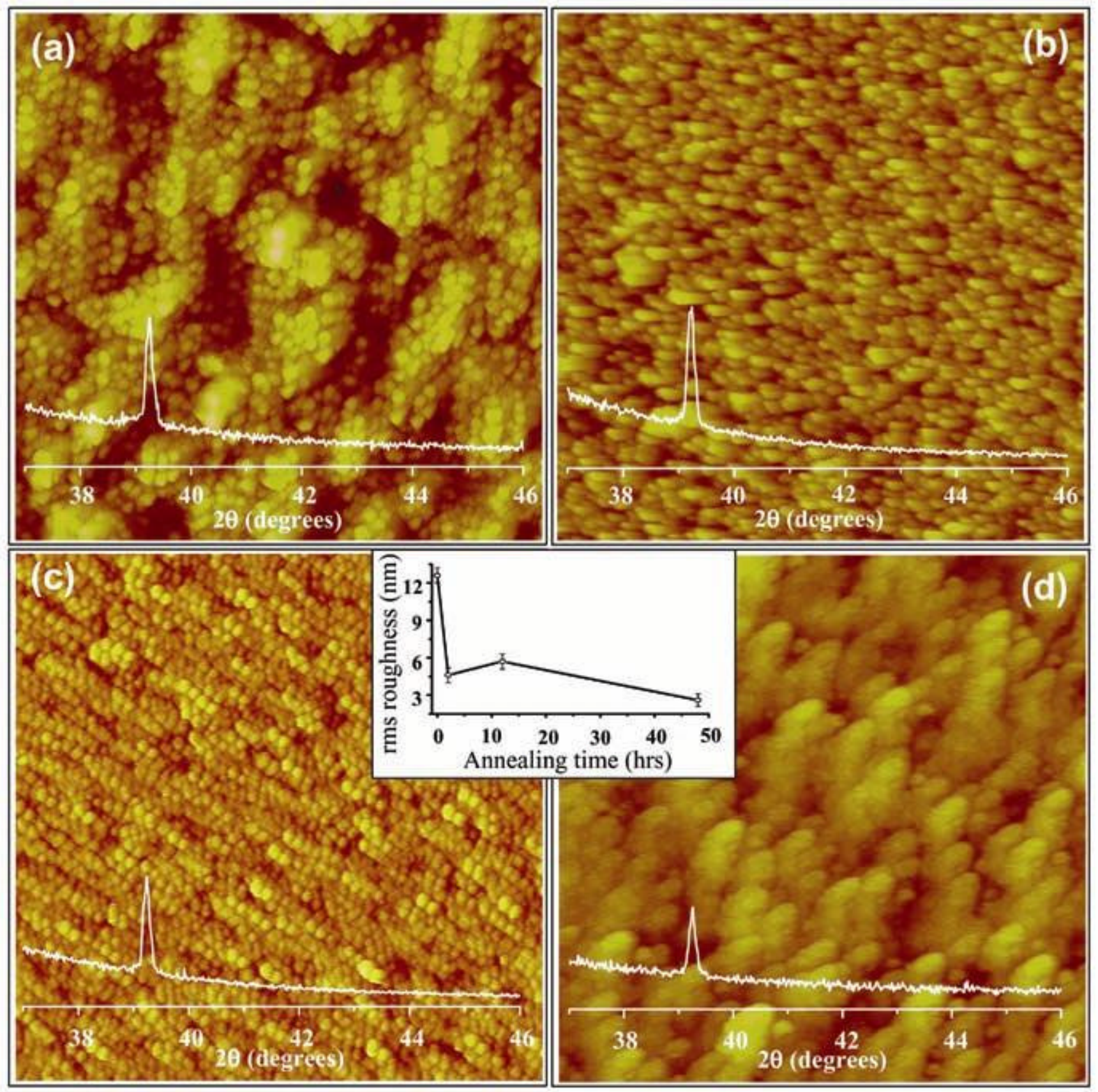

Figure 4. Tapping mode AFM images $\left(2 \times 2 \mu \mathrm{m}^{2}\right)$ obtained after annealing an $\mathrm{Au}$ film at $250^{\circ} \mathrm{C}$ for different time durations: (a) as prepared $(0 \mathrm{~h}),(\mathbf{b}) 2 \mathrm{~h},(\mathbf{c}) 12 \mathrm{~h}$ and (d) $48 \mathrm{~h}$. Variation in the rms roughness values estimated from AFM analysis is shown in the centre. The film was prepared under standard plating conditions $\left(0 \cdot 1 \mathrm{mM} \mathrm{KAuCl} 4,28^{\circ} \mathrm{C}, 30 \mathrm{~min}\right)$. In each case, the corresponding XRD patterns are shown.

each presumably only a few nanometers in size (see inset in figure $5 \mathrm{~b})$. The $\mathrm{Au}(4 f)$ core level obtained from the films indeed revealed the presence of $\mathrm{Au}^{0}$ and $\mathrm{Au}^{1+}$ species as illustrated in figure $5 \mathrm{c}$ for a PVP concentration of $0 \cdot 1 \mathrm{mM}$ (sample 20). Clearly, the $\mathrm{Au}^{1+}$ species arises due to capping of PVP due to surface $\mathrm{Au}-\mathrm{N}$ or $\mathrm{Au}-\mathrm{C}$ bonds (Tsunoyama et al 2004). The $\mathrm{Au}^{1+}$ concentration in the film increases with the concentration of PVP in the plating solution as shown in the inset of figure 5c. It is possible that PVP arrests the growth of Au particulates, more so when it is in higher concentrations, rendering the film X-ray amorphous.

The mechanical properties of $\mathrm{Au}$ films have been measured by nanoindentation (Salmeron et al 1992; Tan- 

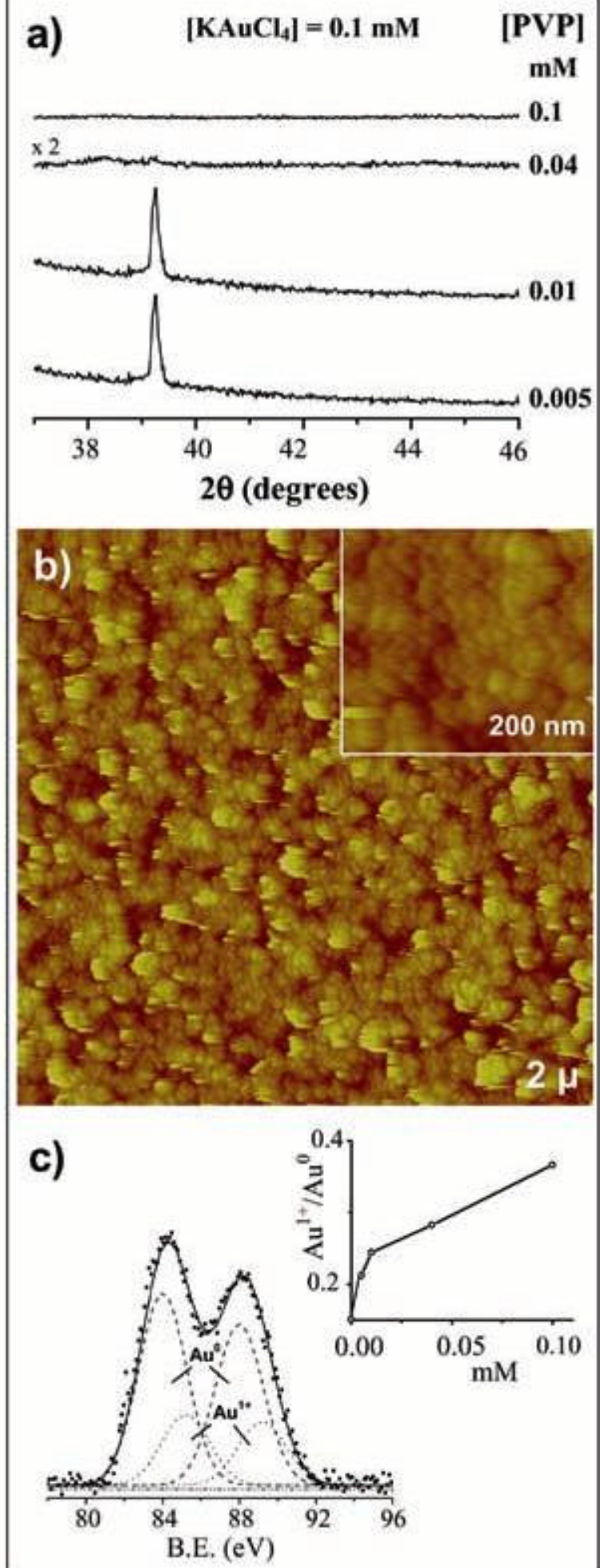

Figure 5. (a) XRD patterns of Au films obtained with different concentrations of poly (vinylpyrrolidone) (PVP) under the standard plating conditions $\left(0 \cdot 1 \mathrm{mM} \mathrm{KAuCl}{ }_{4}, 28^{\circ} \mathrm{C}, 30 \mathrm{~min}\right)$, (b) tapping mode AFM image of an Au film for a PVP concentration of $0.1 \mathrm{mM}$. Inset shows an image from a smaller scan area and (c) $\mathrm{Au}(4 f)$ core-level spectrum of the film. The presence of $\mathrm{Au}^{1+}$ and $\mathrm{Au}^{0}$ species is revealed following Gaussian fitting. Inset shows variation in $\mathrm{Au}^{1+} / \mathrm{Au}^{0}$ with PVP concentration.

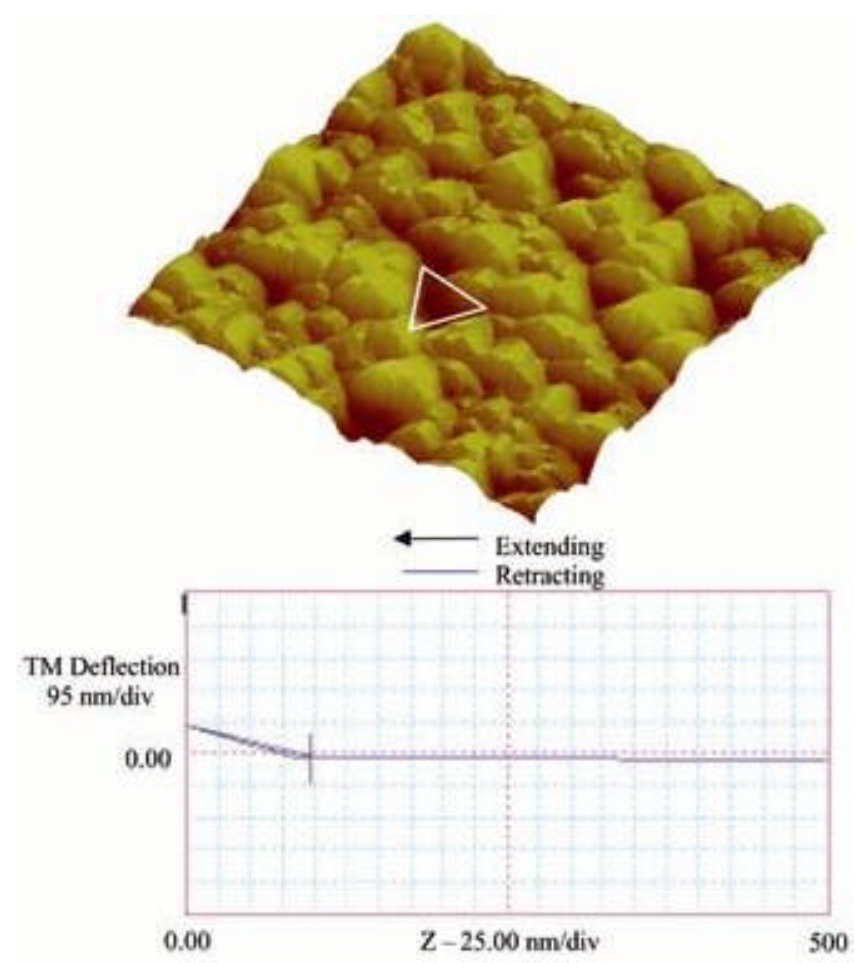

Figure 6. Tapping mode image of the film (sample 2) $\left(1 \times 1 \mu \mathrm{m}^{2}\right)$ showing the indented region. The corresponding $F-$ $d$ curve is shown below.

gyunyong et al 1993; Volinsky et al 2004; Šiller et al 2005). Figure 6 shows the AFM image of an indented region (sample 2, see table 1) along with the force-distance response. The projected area of the indented surface is estimated to be $8321 \mathrm{~nm}^{2}$. The hardness was calculated using the formula,

$$
H=F / A,
$$

where $F$ is the applied force and $A$, the projected area of indentation (Arnault et al 2002). The estimated hardness of the $\mathrm{Au}$ film is $2 \cdot 19 \pm 0 \cdot 1 \mathrm{GPa}$. While bulk Au has much lower hardness $(0.64 \mathrm{GPa})$, the obtained value may be compared with the hardness of sputtered Au films (2.01 GPa) (Šiller et al 2005).

\section{Conclusions}

The present study has for the first time, established experimental conditions optimal for electroless deposition of $\mathrm{Au}(111)$ films of desired thickness. Thus, deposition carried out with a plating solution $\left(\mathrm{KAuCl}_{4}\right.$ in $\left.5 \mathrm{M} \mathrm{HF}\right)$ with $0.1 \mathrm{mM}$ of $\left[\mathrm{AuCl}_{4}\right]^{-}$ions at room temperature for $30 \mathrm{~min}$, produces a well-oriented film of thickness, $\sim 29 \mathrm{~nm}$. Higher precursor concentrations, higher temperatures and longer deposition times produce polycrystalline films with increased roughness. For a given concentration of the precursor $(0.1 \mathrm{mM})$, the film thickness is found to increase linearly 
with time $(\sim 1 \mathrm{~nm} / \mathrm{min})$ during the first hour and the growth became much faster at longer durations $(\sim 9 \mathrm{~nm} / \mathrm{min})$, with the film texture turning polycrystalline. Annealing a well-oriented film at $250^{\circ} \mathrm{C}$ for $12 \mathrm{~h}$ reduces the roughness. We have found that PVP as additive to the plating solution, greatly influence the morphology of the resulting films. It produces $\mathrm{X}$-ray amorphous films containing $\mathrm{Au}^{1+}$ species proportional to the PVP concentration itself as evidenced by X-ray photoelectron spectroscopy. The estimated hardness $(2 \cdot 19 \pm 0 \cdot 1 \mathrm{GPa})$ from nanoindentation is similar to that of the sputtered films.

\section{Acknowledgements}

The authors are grateful to Prof. C N R Rao, for useful discussions and encouragement. They thank Dr Gargi Raina, S J Neena and T Vijaykumar for their assistance in measurements. Thanks are also due to Veeco India Nanotechnology Laboratory, JNCASR, for providing the Optical Profiler Facility.

\section{References}

Arnault J C, Mosser A, Zamfirescu M and Pelletier H $2002 \mathrm{~J}$. Mater. Res. 171258

Furukawa S and Mehregany M 1996 Sensors \& Actuators A56 261

Gorostiza P, Servat J, Morante J R and Sanz F 1996 Thin Solid Films 27512

Gorostiza P, Diaz R, Servat J, Sanz F and Morante J R 1997 J. Electrochem. Soc. 144909

Gorostiza P, Kulandainathan M, Diaz R, Sanz F, Allongue P and Morantes J R 2000 J. Electrochem. Soc. 1471026

Homma T, Wade C P and Chidsey C E D 1998 J. Phys. Chem. B102 7919

Hou Z, Abbott N L and Stroeve P 1998 Langmuir 143287

Hou Z, Dante S, Abbott N L and Stroeve P 1999 Langmuir 15 3011

Kalkan A K and Fonash S J 2005 J. Phys. Chem. B109 20779

Khoperia T N, Tabatadze T J and Zedgenidze T L 1997 Electrochimica Acta 423049
Kobayashi T, Ishibashi J, Mononobe S, Ohtsu M and Honma $\mathrm{H}$ 2000 J. Electrochem. Soc. 1471046

Krikshtopaitis I B and Kudzhmauskaite Z P 1971 Elektrokhimiya 71679

Kuwahara Y, Natatani S, Takahasi M, Aono M and Takahashi T 1994 Surf. Sci. 310226

Kuznetsov G V, Skryshevsky V A, Vdovenkova T A, Tsyganova A I, Gorostiza P and Sanz F 2001 J. Electrochem. Soc. 148 C528

Li L B, An M Z and Wu G H 2005 Mater. Chem. Phys. 94159

Magagnin L, Maboudin R and Carraro C 2001 Electrochem. Solid State Lett. 4 C5

Magagnin L, Maboudian R and Carraro C 2002 J. Phys. Chem. B106 401

Magagnin L, Maboudian R and Carraro C 2003 Thin Solid Films 434100

Mallory G O and Hajdu J B (eds) 1990 Electroless plating: Fundamentals and applications (Orlando, Florida: AESFS)

Morinaga H, Suyama M and Ohmi T 1994 J. Electrochem. Soc. 1412834

Nagahara L A, Ohmori T, Hashimoto K and Fujishima A 1993 J. Vac. Sci. Technol. A11 763

Norga G J, Platero M, Black K A, Reddy A J, Michel J and Kimerling L C 1997 J. Electrochem. Soc. 1442801

Okinaka Y and Hoshino M 1998 Gold Bull. 313

Osaka T, Takano N and Yokoshima T 2003 Surf. Coating Tech. 169-170 1

Pearlstein F and Lowenheim F A (ed.) 1974 Modern electroplating (New York: Wiley)

Salmeron M, Folch A, Neubauer G, Tomitori M, Ogletree D F and Kolbe W 1992 Langmuir 82832

Shacham-Diamond Y, Inberg A, Sverdlov Y and Croitoru N 2000 J. Electrochem. Soc. 1473345

Šiller L, Peltekis N, Krishnamurthy S and Chao Y 2005 Appl. Phys. Lett. 86221912

Sugimura H and Nakagiri N 1995 J. Vac. Sci. Technol. B13 1933

Tangyunyong P, Thomas R C, Houston J E, Michalske T A, Crooks R M and Howard A J 1993 Phys. Rev. Lett. 713319

Tsunoyama H, Sakurai H, Ichikuni N, Negishi Y and Tsukuda T 2004 Langmuir 2011293

Volinsky A A, Moody N R and Gerberich W W 2004 J. Mater. Res. 192650

Warren S et al 2002 Surf. Sci. 496287 